\title{
PROPRIEDADE INTELECTUAL E SOBERANIA
} NACIONAL: ANÁLISE DO ACORDO DE SALVAGUARDAS TECNOLÓGICAS ENTRE BRASIL E ESTADOS UNIDOS PARA O CENTRO ESPACIAL DE ALCÂNTARA

\author{
BRUNA SAMPAIO SILVA', CAROLINA RAMOS FELTRIN ${ }^{2}$
}

\section{RESUMO}

Em março de 2019, o presidente Jair Bolsonaro viajou aos Estados Unidos e diversos acordos bilaterais foram firmados. Dentre eles, o Acordo de Salvaguardas Tecnológicas, que prevê a proteção de dados de tecnologia dos norte-americanos em troca do uso do Centro Espacial de Alcântara baseado em Maranhão, para o lançamento de foguetes e espaçonaves. Pontos do acordo, como o acesso a áreas restritas e controladas, com permissões de acesso concedidas apenas por agentes autorizados pelo governo dos Estados Unidos, levantam um alerta sobre a garantia da soberania brasileira e abrem espaço para discutir como os direitos de propriedade intelectual podem ser instrumentos de influência e coerção sobre os países com baixo desenvolvimento tecnológico, evidenciando a dependência tecnológica que estes países são reféns. A detenção dos direitos de propriedade intelectual asseguram imposição de exigências no Acordo de Salvaguardas Tecnológicas, exigências que não somente são potencialmente lesivas à soberania nacional, mas igualmente criam obstáculos para um desenvolvimento endógeno, reforçando ainda mais a condição de dependência tecnológica. Diante disso, o artigo analisa como o histórico e as projeções para o Programa Espacial Brasileiro, especialmente para a Base de Alcântara, se relacionam com estas questões.

PALAVRAS-CHAVE: Base de Alcântara, Acordo de Salvaguardas Tecnológicas, Direitos de Propriedade Intelectual.

\begin{abstract}
In 2019, Brazil has signed a Technological Safeguards Agreement with United States that foresees North American's data protection in exchange of the use of Alcantara base Space Center, located in Maranhão, Brazil to rocket and spaceships launching. However, there are points on the agreement like the access allowances given only by USA authorized agents, that raise an alert about the assurance of Brazil's sovereignty and open a space for discussion on how intellectual property rights can be instruments of influence and coercion towards less technological developed countries, showing the technological dependency that those countries are hostage of. The ownership of the intellectual property rights is what assures the requirements on the technological safe agreements, and those requirements are not only harmful for national sovereignty, but also create obstacles for endogenous development, reinforcing the dependency condition. That said, this work will analyse how the history and projections for Brazil's Space Program, specially concerning Alcantara base, are related to this matter.

KEYWORDS: Alcântara base, Technological Safeguards Agreements, intellectual property rights

\footnotetext{
${ }^{1}$ Discente no Bacharelado em Relações Internacionais na UFABC. E-mail: brunasampaiosilva@hotmail.com

${ }^{2}$ Discente no Bacharelado em Ciências e Humanidades na UFABC. E-mail: carolafeltrin@gmail.com

R. ÎANDÉ - CIÊNCIAS E HUMANIDADES. S. BERNARDO DO CAMPO, V. 4, N. 1, P. 22-33, 2020.
} 


\section{INTRODUÇÃO}

Em visita a Donald Trump em março de 2019, em Washington, o presidente Jair Bolsonaro firmou alguns acordos bilaterais, como a concessão de vistos a cidadãos dos Estados Unidos - unilateralmente, já que vistos não serão concedidos a brasileiros -, a abdicação do Tratamento Especial e Diferenciado no âmbito da Organização Mundial do Comércio (OMC) em troca de apoio da candidatura brasileira à Organização para a Cooperação e Desenvolvimento Econômico (OCDE) e o Acordo de Salvaguardas Tecnológicas (AST), que permite o uso pelos Estados Unidos do Centro Espacial de Alcântara (CEA), baseado no estado do Maranhão, e tem como objetivo, segundo os representantes do governo de Jair Bolsonaro, o desenvolvimento do Programa Espacial Brasileiro (PEB). O acordo foi discutido e aprovado pelo Congresso Nacional, em agosto, posteriormente aprovado no Senado Federal, em novembro, e está em vigor desde dezembro de 2019.

Um AST entre dois países prevê a proteção de tecnologias e patentes, e autorização para o uso destas. Segundo o resumo do acordo, publicado pelos Ministérios da Defesa (MD), Relações Exteriores (MRE) e Ciência, Tecnologia, Inovações e Comunicações (MCTIC), no AST para o uso do CEA, especificamente,

“os Estados Unidos autorizam o
Brasil a lançar foguetes e
espaçonaves, nacionais ou
estrangeiras, que contenham partes
tecnológicas americanas. Em
contrapartida, o Brasil garante a
proteção da tecnologia americana

contida nestes artefatos." (MCTIC, 2019, p.9)

Neste mesmo resumo, é dada forte ênfase de inviolabilidade da soberania nacional. $\mathrm{O}$ discurso tenta diferenciar o novo acordo da tentativa de AST feita em 2000, no governo do então presidente Fernando Henrique Cardoso, criticado e rejeitado justamente por questões que envolviam a ameaça à soberania brasileira. Os diversos trechos do resumo, como na pág. 3 do resumo, nos tópicos " $\mathrm{O}$ acordo ameaça a soberania nacional?” da pág. 12, "Quem vai controlar o centro de lançamentos? Brasil ou Estados Unidos?" na pág. 14, nas páginas 21 e 22 onde novamente a questão da soberania é citada, demonstram a preocupação do governo federal de desvincular o AST atual da tentativa de 2000 e evitar questionamentos sobre o tema.

$\mathrm{O}$ acordo gera otimismo pela possibilidade de finalmente desenvolver o PEB através dos lançamentos, explorar economicamente a Base de Alcântara - extremamente bem localizada, a cerca de dois graus da Linha do Equador - e impulsionar o desenvolvimento socioeconômico da região.

No entanto, o acordo também gera preocupações pertinentes, como os efeitos traumáticos que as comunidades quilombolas novamente poderão passar, as ameaças à soberania brasileira com a inclusão de pontos sobre áreas de acesso autorizado exclusivamente pelos EUA e a subserviência do atual governo brasileiro em relação a Donald Trump - exemplos de alinhamento geopolítico como os citados no primeiro parágrafo revelam uma cessão de elementos por parte do Brasil sem contrapartida dos EUA - deixando em dúvida a defesa da 
prevalência dos interesses brasileiros em acordos como este.

A discussão sobre o acordo, além do alinhamento político do atual governo brasileiro com Donald Trump, será mais profunda. A necessidade de desenvolvimento tecnológico de países em desenvolvimento os deixam vulneráveis e suscetíveis a acordos sobre direitos de propriedade intelectual que não os beneficiam completamente, mas que são indispensáveis para desenvolver o setor escolhido.

No caso do desenvolvimento do setor aeroespacial brasileiro, um acordo como este com os Estados Unidos é imprescindível por eles serem donos da maior parte das patentes sobre os componentes do setor aeroespacial, e qualquer dispositivo lançado que contenha uma peça sequer, requer autorização ou acordo. Apesar da necessidade de um acordo, o AST chama a atenção pela falta de elementos que garantam o compartilhamento de informações tecnológicas que beneficiem o Brasil, barganha que poderia ser feita utilizando o potencial estratégico da localização da cidade de Alcântara, vergonhosamente resumindo todo o acordo a um aluguel da Base.

\section{NASCIMENTO E DESENVOLVIMENTO DO PROGRAMA ESPACIAL BRASILEIRO}

O Programa Espacial Brasileiro teve início na década de 1960, em meio a Guerra Fria, no governo de Jânio Quadros, com a criação do Grupo de Organização da Comissão Nacional de Atividades Espaciais (GOCNAE). De acordo a Política Externa Independente (PEI), o governo buscou alternativas para a cooperação tecnológica que estruturaria o PEB, com pesquisadores estrangeiros, principalmente da Índia (NASCIMENTO, 2013, p.49)

"o programa espacial brasileiro tem apresentado, desde sua origem, a cooperação internacional como uma de suas principais características. Essa cooperação é marcada pelo momento político vivenciado no país e por níveis distintos na efetividade dessas parcerias. É preciso ter em mente que países detentores de tecnologia, tais como EUA e Rússia, são Estados essenciais para se conservar contato, tanto pela questão do domínio das patentes quanto pela possibilidade de parcerias técnicas ou vendas de equipamentos para suporte à indústria nacional." (NASCIMENTO, 2013, p.49)

Muitas modificações e criação de novos organismos para o desenvolvimento do programa espacial foram feitas ao passar dos anos, e estudos indicavam que a única base de lançamentos do Brasil, o Centro de Lançamentos da Barreira do Inferno, localizada em Paramirim, no Rio Grande do Norte, não suportaria as projeções de crescimento para o PEB.

A Base de Alcântara então foi construída e entregue em 1983, localizada em um dos locais mais estratégicos do mundo para o lançamento de foguetes, a cerca de apenas 2 graus ao sul da linha do Equador, o que gera redução nos custos com gasolina e facilita lançamentos em diferentes trajetórias. (Nexo Jornal, 2019)

Desde então, vários acordos e tentativas de desenvolvimento tecnológico têm sido testados - sem sucesso. O último acordo foi em 2006 em parceria com a Ucrânia, que 
resultou na construção de uma empresa binacional, a Alcântara Cyclone Space, que após quase dez anos e quase meio bilhão de reais de investimento, nenhum foguete foi lançado ou sequer desenvolvido; em 2015, a então presidenta Dilma Rousseff pediu a denúncia do acordo, que finalmente em abril de 2019, levou à extinção da empresa binacional.

Além das várias críticas do grande investimento na binacional não ter resultado em desenvolvimento tecnológico ou econômico, documentos revelados pelo WikiLeaks em 2011 mostraram a interferência dos Estados Unidos para impedir a transferência tecnológica da Ucrânia para o Brasil; a Ucrânia, em 2009, teria pedido a ajuda dos EUA para fortalecer o projeto da binacional. Em mensagem do Departamento de Estado dos EUA, a recusa e proposta de boicote levanta o questionamento do cumprimento de um acordo parecido apenas 10 anos após a declaração:

\begin{abstract}
"Queremos lembrar às autoridades ucranianas que os EUA não se opõem ao estabelecimento de uma plataforma de lançamentos em Alcântara, contanto que tal atividade não resulte na transferência de tecnologias de foguetes ao Brasil." (BBC News Brasil, 2019)
\end{abstract}

Apesar da compreensível e necessária desconfiança com os Estados Unidos, um acordo de salvaguardas tecnológicas com os norte-americanos acaba sendo indispensável para o desenvolvimento do setor espacial: eles são detentores das patentes de cerca de $80 \%$ dos componentes do setor aeroespacial (NEXO JORNAL, 2019), ou seja, implica na quase obrigatoriedade dos países que desejam desenvolver o setor façam acordos do tipo com os EUA, inclusive China e Rússia.

Não é a primeira tentativa de um acordo com os EUA. Em 2000, o governo de Fernando Henrique Cardoso tentou negociar um acordo com os Estados Unidos para Alcântara, mas o texto foi rejeitado no congresso nacional com a argumentação de que o acordo feriria a soberania nacional, e de fato, haviam pontos perniciosos, como a entrada de contêineres em território brasileiro que não poderiam ser inspecionados por autoridades brasileiras e a restrição aos recursos gerados por foguetes na Base de Alcântara pelo Brasil.

Para o novo acordo, os Ministérios das Relações Exteriores, da Defesa e da Ciência, Tecnologia, Inovações e Comunicações, frisam que os pontos criticados e rejeitados no antigo acordo foram corrigidos, porém os mesmos pontos que geraram preocupação sobre a soberania nacional brasileira, persistem, além de outros pontos preocupantes que contradizem a ênfase da defesa nacional e desenvolvimento da tecnologia espacial no Brasil.

\section{O NOVO ACORDO DE SALVAGUARDAS TECNOLÓGICAS PARA O CENTRO DE LANÇAMENTOS DE ALCÂNTARA}

Desde as primeiras definições do AST entre Brasil e Estados Unidos para o uso da Base de Alcântara, é possível observar que não é um acordo simétrico e tem teor puramente restritivo de acesso, com o enfoque maior na proteção dos dados de tecnologia dos norte-americanos e seus direitos sobre a Base de Alcântara do que a transferência e o desenvolvimento tecnológico que o Brasil 
teria acesso, não especificados em nenhum artigo ou parágrafo do acordo.

No artigo II do acordo, define-se então, os tipos de veículos e modalidades a serem lançadas, como veículos lançadores e espaçonaves dos Estados Unidos da América, espaçonaves do Brasil, veículos de lançamento estrangeiros, espaçonaves estrangeiras, equipamentos de apoio e dados técnicos - de manutenção, reparo, processos e afins.

O mesmo artigo define também as ações, atividades e conceitos, e já começa a contradizer as falas enfáticas de autoridades brasileiras governistas contra as acusações de cessão do território e autonomia brasileiros aos norte-americanos. No parágrafo 14, são definidas as "áreas restritas", aquelas que pertencem ao território brasileiro e que somente será permitido o

acesso a pessoas autorizadas pelo
Governo dos EUA, a fim de
assegurar que, de maneira
ininterrupta, possam monitorar,
inspecionar, acessar e controlar o
acesso a Veículos de Lançamento
dos EUA, Espaçonaves dos EUA,
Equipamentos Afins e/ou Dados
Técnicos, para fins de realizar
Atividades de Lançamento.
(GOVERNO FEDERAL, 2019, p. 6)

Ou seja, com a justificativa de proteger os dados técnicos e equipamentos norte-americanos, é conferido o direito aos Estados Unidos de terem jurisdição sobre parte do território brasileiro, podendo proibir as próprias autoridades brasileiras de acessarem parte do território nacional.

O artigo IV fala sobre o Controle de Acesso, que coloca sob responsabilidade do Brasil garantir o acesso dos Estados Unidos a áreas restritas, assim como o monitoramento eletrônico que os norte-americanos acharem necessário para as áreas dentro da base.

No parágrafo 6 deste artigo, é exigida a identificação por crachás com nome e foto de brasileiros que acessem as áreas restritas controladas pelos Estados Unidos, sem que o contrário, a identificação dos norte-americanos, seja feita também. Também é colocada como responsabilidade do Brasil a segurança de todas as áreas ao redor das áreas restritas, que tem a segurança garantida pelos próprios EUA.

$\mathrm{O}$ artigo VII fala sobre os procedimentos operacionais, como transporte, inspeção, imigração e alfândega. Os controles de imigração e alfândega serão os estabelecidos por lei brasileira, com o comprometimento das autoridades brasileiras a acelerar os processos como a concessão de vistos para os norte-americanos.

No entanto, nos casos de inspeção de contêineres requisitados pelo governo brasileiro, essa inspeção só poderá ser feita na presença de norte-americanos, que deverão apresentar um documento de declaração de conteúdo. A garantia de que os agentes norte-americanos não carregarão material não relacionado às atividades de lançamento, será prestada ao próprio governo dos Estados Unidos, como descrito no item $\mathrm{C}$ do parágrafo 1. Em outras palavras, a discriminação e garantia de segurança sobre um conteúdo estrangeiro em território brasileiro, será dada aos Estados Unidos, e não às autoridades brasileiras.

Sobre os preparativos de lançamento, o parágrafo 2 descreve que todo $\mathrm{o}$ acompanhamento dos brasileiros nesses 
procedimentos deverá ser feito mediante autorização e supervisão dos Estados Unidos, e o papel de garantia de segurança nos procedimentos de lançamento - não permitir o acesso de não norte-americanos - será do garantirão que brasileiros não acessem parte do processo.

Somente a participantes norte-americanos é permitido o abastecimento, a montagem, desmontagem, testes e transporte de Veículos de Lançamento e Espaçonaves dos Estados Unidos da América. Após o lançamento, é dever de ambos os participantes, brasileiros e norte-americanos, garantirem que as peças sejam transportadas para fora do território brasileiro ou destruídas.

O AST só limita e descreve como deve ser garantida a segurança de veículos de lançamento e espaçonaves dos Estados Unidos dentro da Base de Alcântara, impondo restrições a parceiros comerciais e o acesso a partes do território brasileiro para interferência externa. Apesar de no resumo publicado pelo MCTIC (2019) o Ministro Marcos Pontes dizer que a expectativa é a de cooperação tecnológica (MCTIC, 2019, p. 3), em nenhum artigo do acordo integral é especificado de que forma isso aconteceria, e no próprio resumo essa fala é contradita, dizendo que não há previsão de transferência tecnológica (MCTIC, 2019, p. 17).

\section{DIREITOS DE PROPRIEDADE INTELECTUAL COMO INSTRUMENTO GEOPOLÍTICO}

Países em Desenvolvimento, como o Brasil, tiveram pouco tempo de investimento maciço Brasil, em outras palavras, brasileiros que consigam usar a Base sem qualquer

em indústria e tecnologia e ao longo de suas histórias acabam enfrentando impasses como o de não desenvolvimento de setores estratégicos que utilizam tecnologia avançada, como o espacial, ou enfrentando acordos em que os direitos de propriedade intelectual acabam impedindo o acesso a tecnologias.

$\mathrm{O}$ que assegura a imposição de tais exigências são a detenção dos direitos de propriedade intelectual, cerne do acordo. Segundo Díaz (2008), direitos de propriedade intelectual são a conversão legal do conhecimento e informação, bens intangíveis, em bens tangíveis, mercadologicamente transacionáveis e privados. O objetivo de garantir esses direitos, também, é incentivar a produção desta informação e conhecimento assim como sua difusão no corpo social através do retorno financeiro obtido (DÍAZ, 2008). Outrossim, há normas que estabelecem detenção de direitos econômicos, exclusivos e temporários sobre criações, e também controle sobre o conhecimento e informação para haver proteção e restrição ao acesso a essas informações e conhecimento (DÍAZ, 2008).

Além da objetificação do conhecimento, a propriedade intelectual estabelece relações de "direitos e deveres, faculdades e exclusões a partir de uma série de regras que estão se globalizando aceleradamente graças à convênios multilaterais e tratados de livre comércio 3" (DÍAZ, 2008, p. 1). Os ASTs, então, são resultados em forma de regra normativa da globalização dos direitos de propriedade intelectual.

Os ASTs afirmam o "compromisso mútuo de proteger as tecnologias e patentes da outra

${ }^{3}$ Tradução do autor

R. ÎANDÉ - CIÊNCIAS E HUMANIDADES. S. BERNARDO DO CAMPO, V. 4, N. 1, P. 22-33, 2020. 
parte contra uso ou cópia não autorizados" (AEB, 2017a, apud ANDRADE et al., 2018 p. 23). O acordo em questão, especialmente, resguarda a licença para importação e uso de materiais de lançamento de satélites, permitindo que somente os Estados Unidos autorizem quem poderá acessar os materiais que possuam suas tecnologias.

O acordo também barra formalmente a utilização dos recursos derivados do uso da Base de Alcântara para desenvolver, testar, produzir ou utilizar dispositivos que se enquadrem na Categoria I ${ }^{4}$ do MCTR ou seja, o acordo impede também o desenvolvimento próprio de tecnologia a partir dos recursos do acordo.

Deste modo, a tecnologia é utilizada unilateralmente, bloqueando assim o fluxo de conhecimento e desenvolvimento, e atenuando as assimetrias entre países desenvolvidos e em desenvolvimento. A detenção dos direitos de propriedade intelectual sobre a tecnologia, é o que assegura a posição sobrepujante nos acordos de negociação, abrindo espaço e aferindo poder de exigência quase que ilimitado aos detentores da tecnologia.

Historicamente, uma das explicações dos EUA serem tecnologicamente desenvolvidos e depositários quase que monopolistas de direitos de propriedade intelectual, é através do impulso gerado pela crise de déficits na balança comercial nos anos 1970 e 1980. Quando enfrentaram a crise, os EUA precisaram transformar sua base econômica, majoritariamente industrial, para o investimento pesado em ciência e tecnologia.

\footnotetext{
${ }^{4}$ Mísseis, Foguetes e VANT completos, assim como maiores subsistemas e suas instalações de produção (BRANCO, 2011)
}

Assegurar estes investimentos era então crucial. Este cenário culminou nos pleitos e ofensivos a um acordo internacional sobre propriedade intelectual. O início preambular de produção tecnológica associada posteriormente aos direitos de propriedade intelectual desse investimento no âmbito internacional, foi elementar.

É indispensável abordar também como os organismos internacionais, o sistema internacional de comércio e seus acordos adjacentes, em especial o TRIPS (Agreement on Trade-Related Aspects of Intellectual Property Rights), corroboram para a ocorrência dessas lesões de soberania em função da propriedade intelectual, respaldando e estimulando o padrão de assimetria tecnológica observado entre países que possuem grandes corporações e tecnologia desenvolvida, e os que não possuem.

O TRIPS é um tratado designado aos países membros da Organização Mundial do Comércio (OMC), firmado em 1994 na Rodada Uruguai, que rege normas internacionais de proteção a direitos de propriedade intelectual, sendo os países signatários obrigados a respeitar os padrões mínimos do TRIPS e incorporá-los às normas tangentes à propriedade intelectual. É essencial atentar-se também ao fato de que quem pleiteou a efetivação do TRIPS foi os Estados Unidos, que já estava lançado nos anos 1990 de maneira enérgica no setor de ciência e tecnologia. Segundo Domingues:

“As regras estabelecidas no TRIPS
reduzem de forma significativa a
autonomia dos Estados Nacionais de
disporem de políticas próprias de
proteção em matéria de propriedade
intelectual compatíveis com suas 
necessidades de desenvolvimento. Por exemplo, nos termos das regras do acordo TRIPS, a engenharia reversa e outros métodos legítimos de difusão e transferência de conhecimento são restringidos." (DOMINGUES, 2003, p. 86)

Para Kennedy e Lim (2018), estados ascendentes e de renda média como o Brasil, adquirem tecnologia de 3 formas: making, transacting e taking. A forma making diz respeito ao apoio ao produtor doméstico de tecnologia, ou seja, produção de tecnologia via pesquisa, sendo este um investimento de longo prazo. Já o meio transacting concerne às transações comerciais, como a compra e licença para uso de tais tecnologias, envolvendo cooperação mútua. A forma taking envolve aquisição de tecnologia já existente por meios não transacionais, e o fluxo de tecnologia é passado dos países mais tecnologicamente desenvolvidos aos menos.

Os ASTs visam barrar a forma taking de aquisição tecnológica. O Brasil é um país de renda média que não produz tecnologia no modo making. Segundo Kennedy e Lim: "Um dado estado pode investir muito pouco em making, por exemplo, tornando-o mais dependente de fontes externas de tecnologia. Brasil e Índia caíram tipicamente neste padrão 5 ." (KENNEDY, LIM, 2018, p. 557)

Díaz (2008) também sinaliza assimetria entre o desenvolvimento e produção de ciência e tecnologia entre os países desenvolvidos e em desenvolvimento. Coloca que tal assimetria e dependência de tecnologia externa perdurará caso os países não invistam em pesquisa e desenvolvimento, porém os países em desenvolvimento encontram barreiras além da própria força política para o desenvolvimento tecnológico e científico, como continua pontuando Díaz, dizendo que essa falta de produção é onerosa e ligada à obrigação dos tratados de livre comércio e ao vínculo com o tratado de cooperação em matéria de patentes.

A dependência dos componentes patenteados para construção de dispositivos aeroespaciais impede o Brasil então de lançar os dispositivos de forma autônoma, e tais lançamentos somente foram viabilizados via um acordo que barra uma forma de aquisição tecnológica.

Ainda criticando as adversidades que podem criar os direitos de propriedade intelectual, Díaz coloca que eles "contribuem para criar monopólios que encarceram o consumo de novos bens e serviços, e inclusive podem frear as inovações subsequentes, dificultando o progresso tecnológico ." (DÍAZ, 2008, p. 31)

As patentes não necessariamente podem ser abordadas de uma forma simplista como um simples método de registro, mas como "um sistema que estabelece um novo território de direitos, mais ou menos discutíveis que podem ou não ter valor comercial. Isso configura um cenário complexo para os países em desenvolvimento " (DÍAZ, 2008, p. 38). É desta maneira que o controle das patentes exercido pelos EUA neste AST permite o controle dos lançamentos em Base brasileira, controle de parceiros comerciais do Brasil e exigências sobre o território brasileiro. A relação entre os direitos de propriedade intelectual, poder de exigência e controle territorial é abordada por completo nas diretrizes do acordo, fazendo com que o

\footnotetext{
${ }^{6}$ Tradução do autor
}

7 Tradução do autor

\footnotetext{
5 Tradução do autor

R. ÎANDÉ - CIÊNCIAS E HUMANIDADES. S. BERNARDO DO CAMPO, V. 4, N. 1, P. 22-33, 2020.
} 
valor da propriedade intelectual passe a ser não somente comercial, mas geopolítico. Dada as imposições, os direitos de propriedade intelectual passaram de um artifício de defesa e proteção da inovação para um mecanismo de poder.

Ao longo dos séculos, a fonte de poder e dominação de um Estado em relação a outro alterou-se diversas vezes, segundo Nye (2009). A fonte de poder do século XXI encontra-se na tecnologia, deste modo, os Estados que saíram na frente em sua obtenção e monopolização detêm a ferramenta promissora da dominação e supremacia. Nye (2009) também coloca a prevalência no Séc XXI do "poder brando", isto é, poder derivado de influências, negociações, estabelecimento de crenças e preferências do Estado influenciador. O exercício do poder brando pelos EUA é evidente no que tange ao seu poder de barganha e negociação e imposição. O firmamento do acordo TRIPS, deveras desvantajoso a países com desenvolvimento tecnológico em estágio embrionário, também é uma evidência do poder brando exercido pelos Estados Unidos.

Embora os Ministérios das Relações Exteriores e da Ciência, Tecnologia, Informações e Comunicações enfatizem que o acordo não viola os princípios de soberania, no próprio acordo são descritas formas em que o Brasil garante aos Estados Unidos o direito de decidirem sobre partes do território brasileiro e limitarem os parceiros comerciais do Brasil, além de permitir aos norte-americanos o controle de operação dos lançamentos é uma ferramenta intrínseca ao exercício da soberania, já que assegura funções de comunicação, controle e sensoriamento remoto (ANDRADE et al. 2018).

\section{CONCLUSÃO}

O discurso para a necessidade de um acordo do tipo para acabar com a ociosidade da Base de Alcântara é legítimo, porém enganoso se utilizado para caracterizar este AST entre Brasil e Estados Unidos, que nada tem de vantajoso para o Brasil além dos ganhos com o "aluguel" do CEA, subutilizado se analisado pelos interesses do desenvolvimento do Programa Espacial Brasileiro, e entregue de forma indiscutível aos interesses norte-americanos.

$\mathrm{O}$ acordo discutido tem as mesmas características dos acordos da política externa brasileira do governo Bolsonaro para os Estados Unidos da América: alinhamento acrítico e imediato, sem exigências de contrapartidas, subserviência e com ganhos dificilmente de serem visualizados - se aprofundados -, mas que servem ao discurso populista e de alinhamento a Donald Trump, além de reforçar o discurso e políticas anti-científicas que têm sido adotados desde o começo do mandato de Jair Bolsonaro.

O Acordo de Salvaguardas Tecnológicas para o uso da Base de Alcântara, ao mesmo tempo que ilustra a dependência tecnológica e a vulnerabilidade de países em desenvolvimento, como o Brasil, que dependem de acordos para direitos de propriedade intelectual para desenvolver setores estratégicos em seus países, demonstra também a falta de perspectiva e ambição de um governo para planejar um setor estratégico reforçando a dependência e desestimulando a produção endógena de ciência e tecnologia. Sem iniciar a produção no modo making, realizar acordos nestes termos nunca atenderá aos interesses 
Silva, B; FELTRIN, C.

PROPRIEDADE INTELECTUAL E SOBERANIA NACIONAL

nacionais e só garantirão a posição já

consolidada das potências em ciência e tecnologia.

R. ÎANDÉ - CIÊNCIAS E HUMANIDADES. S. BERNARDO DO CAMPO, V. 4, N. 1, P. 22-33, 2020. 


\section{REFERÊNCIAS BIBLIOGRÁFICAS}

ANDRADE, Israel de Oliveira et al. O CENTRO DE LANÇAMENTO DE ALCÂNTARA: ABERTURA PARA O MERCADO INTERNACIONAL DE SATÉLITES E SALVAGUARDAS PARA A SOBERANIA NACIONAL. Rio de Janeiro: Ipea, 2018. Disponível em: http://repositorio.ipea.gov.br/bitstream/11058/8897/1/td_2423.pdf. Acesso em: 23 de Agosto de 2019.

BBC News Brasil. As polêmicas sobre o acordo entre Brasil e EUA para uso do centro espacial de Alcântara. 20 mar. 2019. BBC News Brasil, São Paulo. Disponível em https://www.bbc.com/portuguese/brasil-47632237. Acesso em: 25 de Agosto de 2019.

DÍAZ, Rafael. La economía de la propiedad intelectual. In: DÍAS, R. América Latina y Caribe: la propiedad intelectual después de los tratados de libre comercio. Santiago do Chile: CEPAL, 2008.

DOMINGUES, Renato Valladares. O DIREITO INTERNACIONAL DA PROPRIEDADE INTELECTUAL E SUA REGULAMENTAÇÃO ATRAVÉS DO ACORDO TRIPS. Escola Superior de Guerra, Rio de Janeiro, v. 20, n. 42, p. 85-89, Janeiro, 2003. Disponível em: https://revista.esg.br/index.php/revistadaesg/article/view/778/702. Acesso em: 25 de Janeiro de 2020.

GOVERNO FEDERAL. Câmara dos Deputados. Mensagem de Acordos, Convênios, Tratados e Atos Internacionais $\mathbf{n}^{\mathbf{0}}$ 208, de 23 de maio de 2019. Acordo Entre O Governo da República Federativa do Brasil e O Governo dos Estados Unidos da América Sobre Salvaguardas Tecnológicas Relacionadas à Participação dos Estados Unidos da América em Lançamentos A Partir do Centro Espacial de Alcântara. Brasília, DF. Disponível em https://www.camara.leg.br/proposicoesWeb/prop_mostrarintegra?codteor=1780003\&filename=MS C+208/2019. Acesso em: 29 de Janeiro de 2020.

KENNEDY, Andrew; LIM, Darren. The innovation imperative: technology and US-China rivalry in the twenty-first century. International Affairs, p. 553-572. maio 2018. Disponível em: https://academic.oup.com/ia/article/94/3/553/4992406. Acesso em: 19 de Julho de 2019.

MCTIC. CONHECENDO O ACORDO DE SALVAGUARDAS TECNOLÓGICAS. Brasília: Ministério das Relações Exteriores, 2019. Disponível em: https://www.mctic.gov.br/mctic/export/sites/institucional/publicacao/arquivos/Entenda-o-AST.pdf. Acesso em: 26 de Agosto de 2019.

MIOTO, Ricardo. WIKILEAKS OS PAPÉIS BRASILEIROS: Ucrânia recorreu aos EUA por foguete com o Brasil. Folha de São Paulo. p. 1-1. jan. 2011. Disponível em: https://www1.folha.uol.com.br/fsp/ciencia/fe2501201101.htm. Acesso em: 23 de Agosto de 2019.

NASCIMENTO, E. C. do. A política espacial brasileira entre 1961-2012: a cooperação Brasil/Ucrânia e a empresa binacional Alcântara Cyclone Space. 2013. 130 f. Dissertação (Programa de Pós-Graduação em Relações Internacionais) - Universidade Estadual da Paraíba, João Pessoa, 2013. Disponível em http://tede.bc.uepb.edu.br/jspui/handle/tede/2061. Acesso em: 25 de Agosto de 2019. 
NEXO JORNAL. O que o acordo da base de Alcântara representa para o Brasil. Nexo Jornal. São Paulo, 292019.2 mar. 20 Disponível em https://www.nexojornal.com.br/expresso/2019/03/29/O-que-o-acordo-da-base-de-Alc\%C3\%A2ntar a-representa-para-o-Brasil. Acesso em: 28 de Janeiro de 2020.

NYE, Joseph S.. O Equilíbrio de Poder e a Primeira Guerra Mundial. In: NYE, J. S. Cooperação e Conflito nas Relações Internacionais. São Paulo: Gente, 2009. 